\title{
Brief Communication: Transplantation of a Human Mammary Carcinoma Cell Line (BT 20) Into Nude Mice ${ }^{1,2}$
}

\author{
L. Ozzello, ${ }^{3}$ B. Sordat, ${ }^{4}$ C. Merenda ${ }^{5}{ }^{5}$ S. Carrel, ${ }^{6}$ J. Hurlimann,${ }^{3}$ and J. P. Mach ${ }^{5}$
}

SUMMARY-Cell suspensions of a human mammary carcinoma cell line (BT 20), when injected subcutaneously into nude athymic mice (BALB/c Nu/Nu), produced tumor nodules at the injection site. Subsequent serial transplantations also gave rise to neoplastic nodules after latency periods averaging 3 weeks. The nodules displayed morphologic and functional characteristics comparable to those of the original tumor cells. Metastases, however, were not observed in any of the tumor-bearing mice.J Natl Cancer Inst 52: 1669-1672, 1974.

THE STUDY of several biologic properties of human mammary carcinomas has been greatly hindered by the lack of suitable experimental models. Thus we have attempted to transplant human mammary tumors and dysplasias into nude athymic mice, which have been successfully used for the transplantation of other human neoplasms (1-3). The present report gives our preliminary results on the transplantation of a human mammary carcinoma cell line (BT 20) which is now in its seventh serial passage in nude mice (BALB/c $\mathcal{N} u / \mathcal{N} u$ ).

\section{MATERIALS AND METHODS}

The BT 20 cell line was started in March 1958 from an infiltrating ductal carcinoma (fig, 1) in a 74-yearold woman (4). Since then, it has exhibited an epithelial growth pattern (fig. 2). These cells are currently grown as monolayers in Falcon plastic flasks with the use of medium RPMI 1640 supplemented with $2 \%$ fetal calf serum.

BT 20 cells from in vitro passage 272 were trypsinized, suspended in a few drops of serum-free medium, and injected subcutaneously (sc) into the subscapular region of 2 nude mice $\left(6.25 \times 10^{6} \mathrm{cells} /\right.$ mouse). One mouse died shortly thereafter without any clinically detectable tumor. The other mouse developed a small nodule detected at the site of injection 41 days after cell transplantation. The nodule grew rapidly and attained a diameter of $\approx 0.5 \mathrm{~cm} 7$ days later. This mouse was killed 52 days after cell transplantation (11 days after the nodule appeared), at which time the nodule was $1.2 \mathrm{~cm}$ in greatest dimension. The nodule was in the soft tissues beneath the sc musculature and was well circumscribed. On section, it was lobulated and composed of soft, pale tissue containing deep-seated foci of necrosis. Prominent vascular channels converging toward or emerging from the nodule were in the adjacent skin and sc tissue. In this experiment, as in subsequent experiments, part of the nodule was removed under sterile conditions and subdivided into small fragments which were transplanted sc into the subscapular region of other female or male nude mice. Other portions of the nodules were utilized for various studies as described below. Consecutive transplantations were carried out similarly and always gave rise to nodules in male as well as in female nude mice after latency periods of $\approx 3$ weeks. The largest nodule measured $2.5 \mathrm{~cm}$ in greatest dimension 49 days after cell transplantation. The seventh serial passage is now in progress (fig. 3). The ease with which BT 20 cells grew in nude mice contrasted sharply with their regular rejection by other experimental animals, except for a temporary acceptance by rats and hamsters observed by Lasfargues et al. (5) after they fused BT 20 cells with normal cells.

\section{RESULTS}

On conventional histologic examination, the nodules were composed of neoplastic epithelial cells forming irregular cords and masses separated by septa of vascularized connective tissue (fig. 4). The tumor cells had distinctive invasive properties, despite the deceivingly circumscribed gross appearance, and displayed marked cellular atypia. They had an abundant cytoplasm, nuclei of variable size, and a high mitotic activity. The overall histologic appearance of these cells and their degree of atypia correlated well with those of the tumor from which the BT 20 cell line originated, the only difference being more stroma in the original neoplasm. Likewise, the ultrastructure of the cells (figs. 5A, B) of these nodules was similar to that of the BT 20 cells growing in vitro $(6)$ and to that of human mammary carcinomas in general (7). The cytoplasnic organelles varied in their distribution from cell to cell, which suggested different functional states of these cells. Many neoplastic cells contained fine filaments located in any portion of the cytoplasm and oriented randomly, except for some peripheral bundles converging toward desmosomes. Membrane-bound osmiophilic secretory granules were rare. Intercellular and intracellular lumens were fairly frequent. The infiltrative nature of the neoplastic cells was particularly evident with the electron microscope: The cells penetrated in to the stroma and the surrounding tissues of the host without ever presenting an interposed basal lamina. The stroma of these nodules was produced entirely by the mouse, since only human mammary carcinoma cells

\footnotetext{
1 Received February 6, 1974; accepted February 21, 1974. 2 Received February 6, 1974; accepted February 21 , Cancer Research, 1011 Lausame, Switzerland, and from the Swiss National Foundation for Scientific Research.

${ }^{3}$ Department of Pathology, University of Lausanne, 1011 Lausanne, Switzerland.

${ }^{4}$ Department of Immunology and Cell Biology, Swiss Institute for Experimental Cancer Research, 1011 Lausanne.

${ }^{5}$ Department of Biochemistry, University of Lausanne.

${ }^{8}$ Ludwig Cancer Research Unit, Swiss Institute for Experimental Cancer Research.
} 
were primarily injected. It consisted of fibroblasts, collagen, rare bundles of elastic fibers, and thin-walled vascular channels. Rarely, it was infiltrated by inflammatory cells including histiocytes, granulocytes, plasma cells, and lymphoid cells. The vascular channels within the tumors were surrounded by a basal lamina and were lined by thin endothelial cells featuring a moderate number of vesicles and rare fenestrations. The infrequency of the fenestrations was in contrast with the many fenestrae seen in the vessels adjacent to the nodules. Pericytes were rare. Whether the newly formed vascular channels resulted, at least in part, from an angiogenic stimulus exerted by the neoplastic cells remains to be determined.

Our observations thus indicate that BT 20 cells, when transplanted into nude mice, can produce tumors morphologically comparable to the original mammary carcinoma, even after 15 years of cultivation in vitro. Studies are now under way to determine whether passage through the mouse is modifying other properties of these cells. Some pertinent observations are:

1) When fragments of neoplastic nodules were reexplanted in vitro under the same conditions as the BT 20 cell line, a monolayer was formed without difficulty and exhibited the same pattern as that of the original cultures. A few fibroblast-like cells, considered mouse cells, were visible at first but disappeared in subsequent passages in vitro.

2) With the use of a technique previously described by Hurlimann and Zuber (8), short-term cultures of minced tissue from the neoplastic nodules, when fed a serum-free medium containing ${ }^{14} \mathrm{C}$-labeled amino acids, revealed an uptake of up to $40 \%$ of the label, which indicated that such tumor cells actively synthesized proteins.

3) To date, electron microscopic screening has disclosed no viral particles in either the neoplastic nodules or in the BT 20 cultures.

4) Metastatic dissemination from the tumor nodules has not yet been observed. Likewise, intravenous injection of BT 20 cells has produced no detectable tumors. We cannot explain this observation. Possibly the time required for metastases to become clinically or histologically manifest may be longer than that which we allowed for our tumors to grow in any one mouse. Also, nude mice may be in some way "resistant" to metastasis of heterografted tumor cells. Indeed, in our experience (3) and the experience of other laboratories (1), human colonic carcinomas that had metastasized in patients failed to metastasize after transplantation into nude mice. On the other hand, metastases from human malignant melanomas growing in outbred nude mice have been observed by Giovanella et al. (2).

\section{CONCLUSION}

These observations suggest that nude athymic mice are a suitable model for experimentation with human breast cancer. We are further encouraged in this conclusion by our preliminary observations on the survival of solid carcinomas and dysplastic lesions of the human mammary gland transplanted into nude mice. The dysplasias, in particular, appear to survive remarkably well in nude mice.

\section{REFERENCES}

(1) Povlsen GO, Rygaard J: Heterotransplantation of human adenocarcinomas of the colon and rectum to the mouse mutant nude. A study of nine consecutive transplantations. Acta Pathol Microbiol Scand [A] 79: 159-169, 1971

(2) Giovanella BC, Y $\mathrm{Im}$ SO, Morgan AC, et al: Metastases of human melanomas transplanted in "nude" mice. $\mathrm{J}$ Nati Cancer Inst 50:1051-1053,1973

(3) Sorda'l B, Frir'sché R, MAGu JP, et al: Morphological and functional evaluation of human solid tumors serially transplanted into nude mice. In Proceedings lst International Workshop on Nude Mice, Scanticon, Aarhus, Denmark, 1973. In press

(4) Lasfargues EY, Ozzelzo L: Cultivation of human breast carcinomas. J Natl Cancer Inst 21:1131-1147, 1958

(5) Lasfargues EY, Coutinho WG, Moore DH: Heterotransplantation of a human breast carcinoma cell line. Cancer Res 32:2365-2368, 1972

(6) OzzelLo L: Ultrastructure of human mammary carcinoma cells in vivo and in vitro. $J$ Natl Cancer Inst 48:1043-1050, 1972

(7) - Ultrastructure of the human mammary gland. In Pathology Annual (Sommers SC, ed.). New York, Appleton-Century-Crofts, 1971, pp 1-59

(8) Hurlimann J, Zuber G: In vitro protein synthesis by human salivary glands. I. Synthesis of salivary IgA and serum proteins. Immunology 14:809-817, 1968 


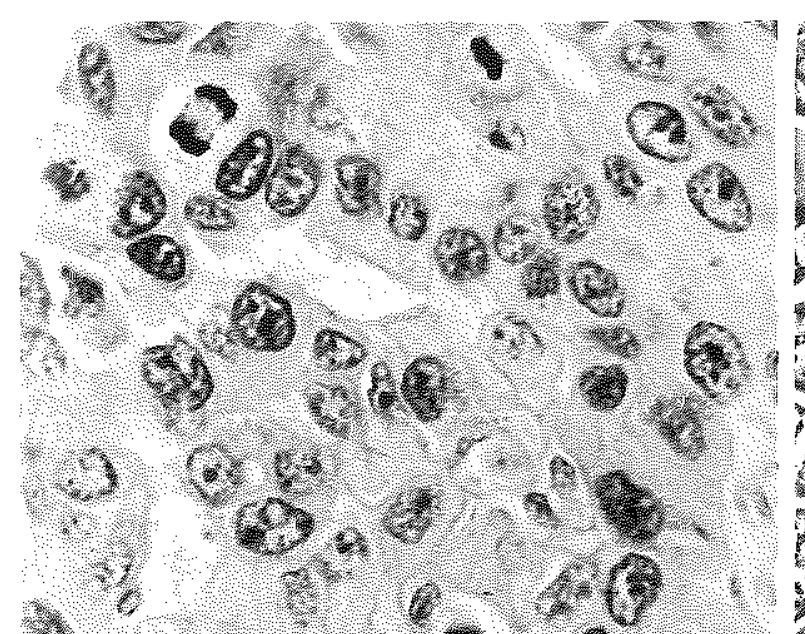

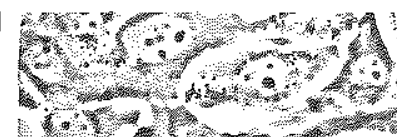

6.6.

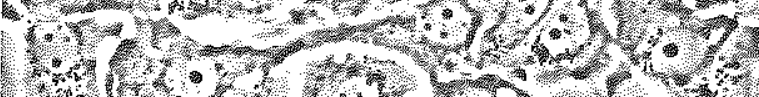

(j)

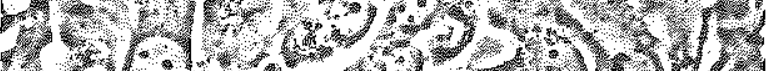

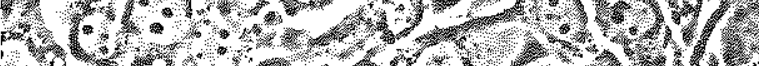

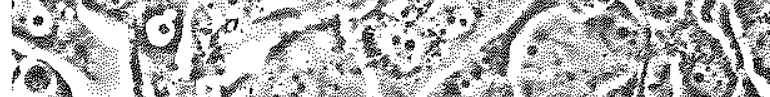

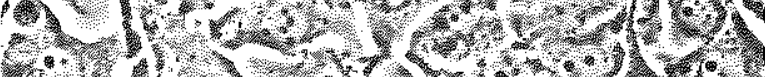

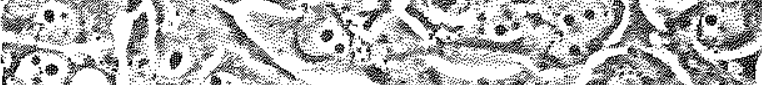

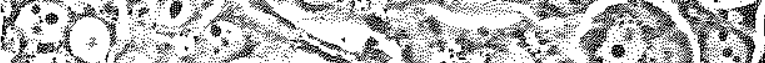

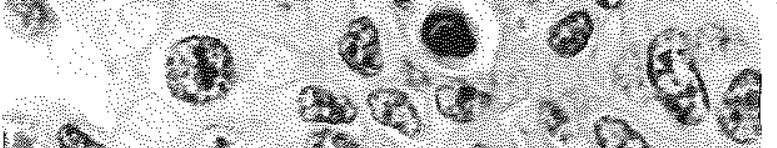

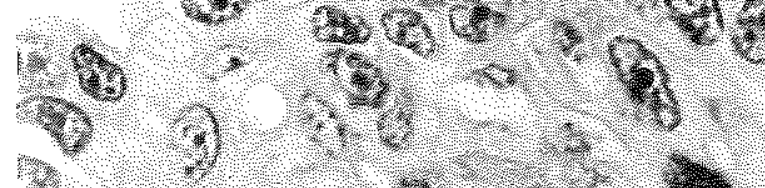

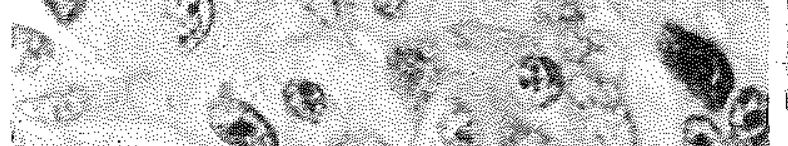

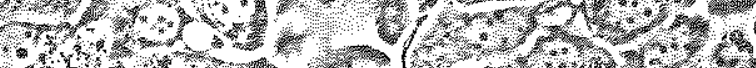

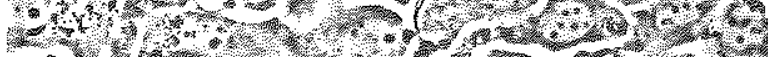

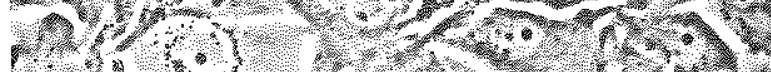

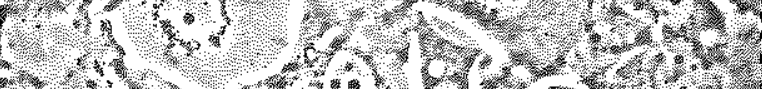

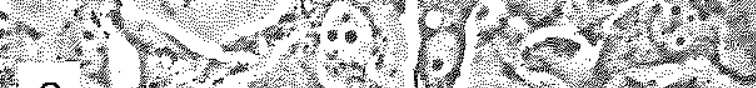

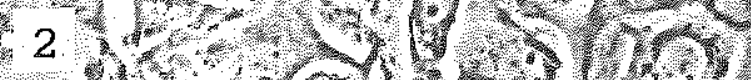
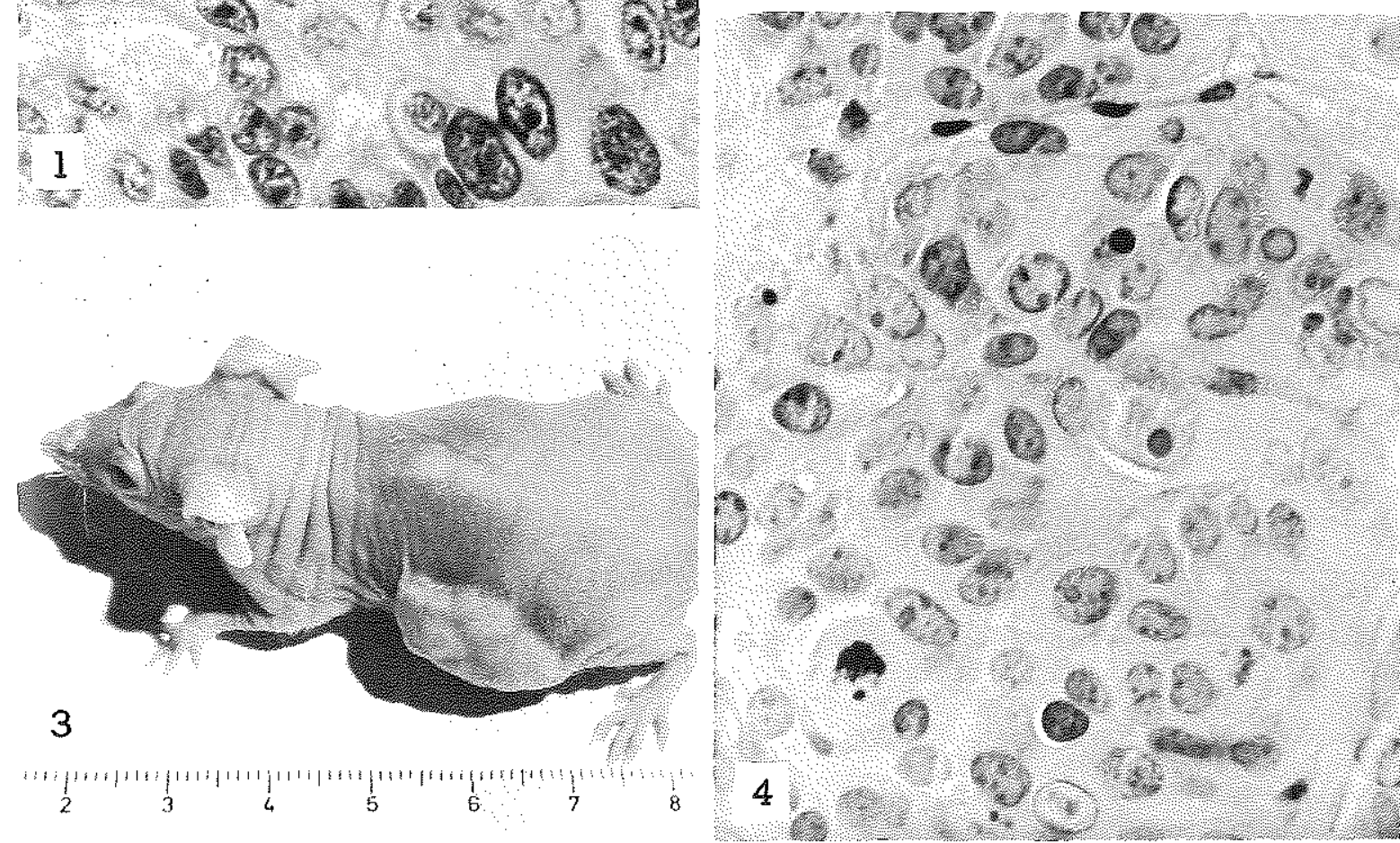

FIGURE 1.- Infiltrating ductal carcinoma from which the BT 20 line was prepared in 1958. Hematoxylin and eosin. $\times 600$

Figure 2.-BT 20 cells, passage 216 in vitro. Phase contrast. $\times 250$

FIGURE 3.-BT 20 tumor in nude mouse, 40 days after passage 7.

Figure 4.-BT 20 tumor in nude mouse, 37 days after passage 3 . Hematoxylin and eosin. $\times 600$ 


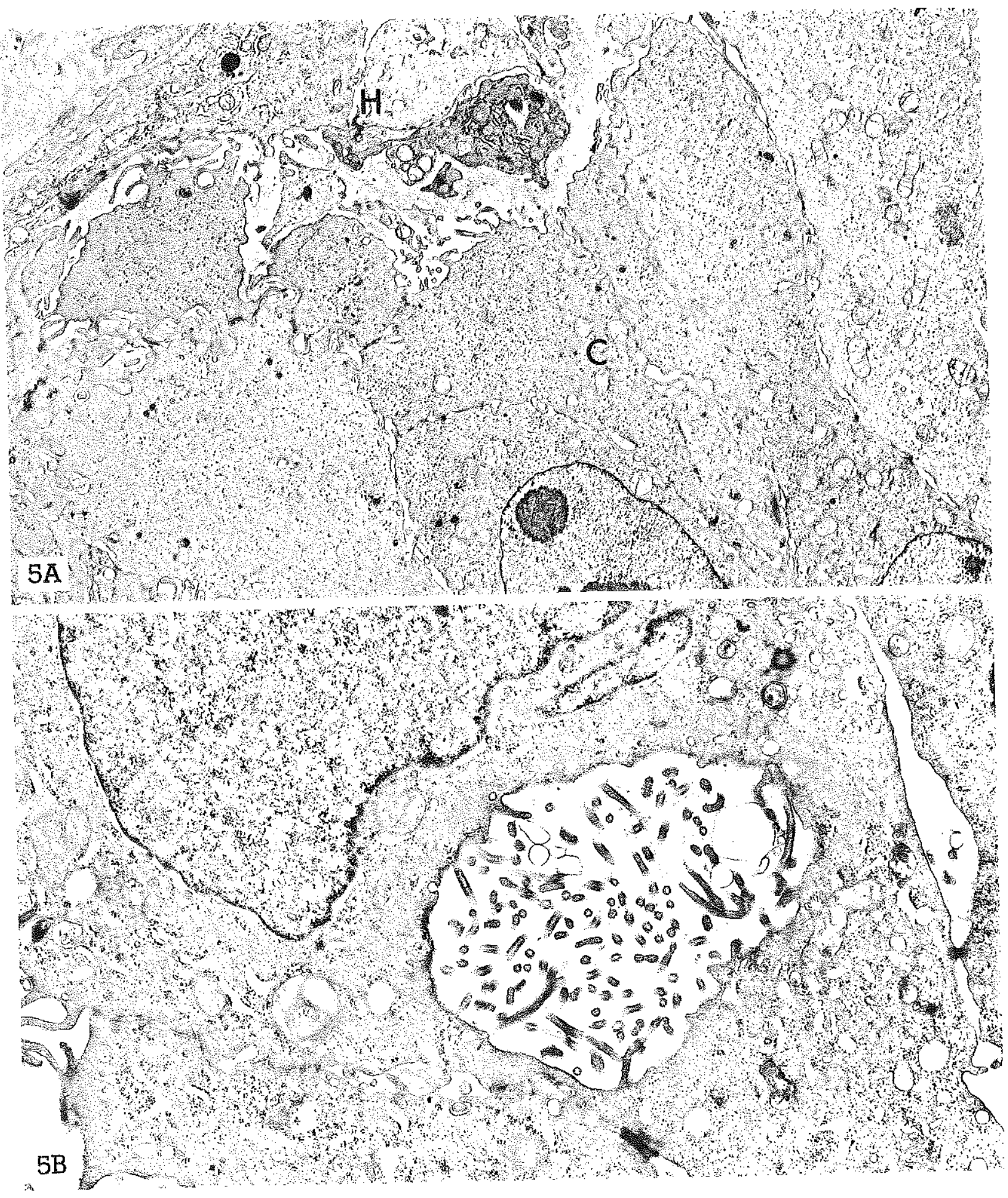

T 20 tumor, 52 days after first transplant in nude mouse: A) Periphery of nodule showing invading carcinoma cell Figuke 5.-BT 20 turo cells (H). $\times 6500$; B) higher magnification of the carcinoma cells (C) with pseudopod-like projections and no
showing an intracellular lumen. $\times 13,000$ 